Original Research Paper

\title{
Sosialisasi Berwirausaha Guna Menambah Penghasilan Pemain Sepakbola PSGS Gunungsari pada Masa Kompetisi Diliburkan Akibat Pandemi Covid-19
}

\author{
Nune Wire Panji Sakti ${ }^{1 *}$, Rusdiana Yusuf ${ }^{1}$, Adi Suriatno ${ }^{1}$, Johan Irmansyah ${ }^{1}$

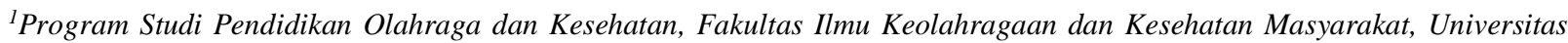 \\ Pendidikan Mandalika, Mataram, Indonesia
}

https://doi.org/10.29303/jpmpi.v3i2.1149

Sitasi: Sakti, N. W. P., Yusuf, R., Suriatno, A \& Irmansyah, J. (2021). Sosialisasi Berwirausaha Guna Menambah Penghasilan Pemain Sepakbola PSGS Gunungsari pada Masa Kompetisi Diliburkan Akibat Pandemi Covid-19. Jurnal Pengabdian Magister Pendidikan IPA 4(4)

\author{
Article history \\ Received: 10 Oktober 2021 \\ Revised: 30 Oktober 2021 \\ Accepted: 17 November 2021 \\ *Corresponding Author: Nune \\ Wire Panji Sakti, Program \\ Studi Pendidikan Olahraga dan \\ Kesehatan, Program Studi \\ Pendidikan Olahraga dan \\ Kesehatan, Fakultas Ilmu \\ Keolahragaan dan Kesehatan \\ Masyarakat, Universitas \\ Pendidikan Mandalika; \\ Email: \\ nunewire90@gmail.com
}

\begin{abstract}
Nasib kompetisi di bidang olahraga ketika diliburkan pada masa Pandemi Covid-19 sangat berdampak bagi para pelaku kompetisi olahraga di Indonesia. Kompetisi olahraga adalah sumber perekonomian bagi semua kalangan, tak hanya pelakunya namun semua kalangan. Ketika wabah pandemi covid-19 datang ke Indonesia, membuat masyarakat khususnya para pelaku yang berkecimpung didunia olahraga menjadi susah dalam memenuhi kebutuhan sehari harinya, akibat lockdown dan turnamen yang di liburkan baik dari tingkat Nasional hingga di pelosok daerah. Hasil observasi baik secara diskusi pada pelaku dunia olahraga khususnya pelaku sepakbola, baik dari panitia turnamen, wasit, manager, pemain tarkam hingga masyarakat daerah Lombok Barat Nusa Tenggara Barat, menerangkan di lokasi pengabdian kompetisi Tarkam adalah sumber mata pencaharian yang menguntungkan baik dari panitia, wasit, pedagang kecil, manager club hingga pemain. Pelaku kompetisi tarkam khususnya pemain kebanyakan anak usia remaja, dewasa yang bekerja di perusahaan, pengangguran, dan lain sebagainya. Pada masa sebelum terjadi pandemi pemain sepakbola tarkam bisa mengumpulkan uang sebesar Rp 20 juta/tahun Perhatian lebih pada pemain remaja di lingkungan masyarakat di lokasi studi memerlukan penanganan, agar tidak terjerumus ke hal-hal negatif yang melanggar hukum. Sehingga dalam upaya tersebut tim mengambil langkah memberikan sosialisasi, motivasi, pelatihan kewirausahaan baik berbentuk jajanan tradisional dan alat olahraga tradisional, dan pelatihan marketing. Mengingat adanya sirkuit balap Mandalika, sehingga kegiatan sosialisasi ini sangat bermanfaat ke depan baik pada masa pandemi berakhir. Beberapa hal di atas tersebut tercetuslah tema pengabdian masyarakat dengan tema Sosialisasi Berwirausaha, Guna Menambah Penghasilan Pemain Sepakbola PSGS Gunungsari Ketika Masa Kompetisi Diliburkan Akibat Pandemi Covid-19.
\end{abstract}

Keywords: Wirausaha; Kompetisi; Sepak bola; Covid-19.

\section{Pendahuluan}

Hadirnya pandemi COVID-19 yang melanda Indonesia dan seluruh negara lainnya mampu mengubah seluruh aspek kehidupan masyarakat. Salah satu yang mengalami perubahan di dalam dunia olahraga adalah kebiasaan yang selama ini dilakukan secara konvensional seperti turnamen, kompetisi di skala Nasional maupun daerah. Dampak nyata pandemi ini membuat seluruh masyarakat terkejut, dimulai dari kurangnya kegiatan yang menghasilkan uang, kurangnya daya 
konsumsi atau daya beli masyarakat menurun akibat COVID-19 (Yuniati \& Amini, 2020).

Nasib kompetisi di bidang olahraga ketika diliburkan pada masa pandemi covid-19 sangat berdampak bagi para pelaku kompetisi olahraga di Indonesia (Hernanda, 2021). Kompetisi olahraga adalah sumber perekonomian bagi semua kalangan, tak hanya pelakunya namun semua kalangan. Ketika wabah pandemi covid-19 datang ke Indonesia, membuat masyarakat khususnya para pelaku yang berkecimpung didunia olahraga menjadi susah dalam memenuhi kebutuhan sehari harinya, akibat lockdown dan turnamen yang diliburkan baik dari tingkat Nasional hingga di pelosok daerah (Lintang Kinasih, 2021). Betapa susahnya segala sesuatu ketika pandemi covid-19 melanda Indonesia, segala upaya pemerintah dalam melakukan cara baik dari pembagian materi akibat dampak pandemi ini sangat baik dilakukan, namun tetap saja masyarakat masih susah dalam kesehariannya. Seperti yang dikatakan beberapa pelaku dunia olahraga, sebut saja Wildan salah satu pemain tarkam di Lombok, yang mengatakan memang benar uang bukan segalanya namun segalanya butuh uang, apalagi di masa pandemi seperti ini, dimana mata pencaharian seperti mati suri, terlebih lagi terkena PHK dari tempat kerja akibat pandemi, covid-19 secara tidak langsung perlahan seperti membunuh financial bahkan para pelaku olahraga baik di tingkat Nasional hingga daerah.

Hasil observasi tim pengabdian baik secara diskusi secara offline maupun daring pada pelaku dunia olahraga di lingkungan saya khususnya pelaku sepakbola, baik dari panitia turnamen, wasit, manager, pemain tarkam yang hampir sebagian menggantungkan kehidupannya dari kompetisi tarkam tersebut. Kompetisi Tarkam adalah sumber mata pencaharian yang lumayan besar menguntungkan beberapa kalangan baik dari panitia, wasit, pedagang kecil, manager club hingga pemain (Noviansyah et al., 2016). Pelaku kompetisi tarkam khususnya pemain kebanyakan anak usia remaja, dewasa yang bekerja di perusahaan, pengangguran, dan lain sebagainya. Pada masa sebelum terjadi pandemi pemain sepakbola tarkam bisa mengumpulkan uang sebesar Rp 20 juta/tahun bahkan lebih.karena di daerah ini ada beberapa klub yang biasa merekrut pemain yang berani membayar mahal bahkan lebih agar bisa menjadi juara di setiap turnamen tarkam, dan timbal baliknya pemilik klub yang biasanya adalah perusahaan, pelaku usaha lainnya menjadi terkenal. Dari penjelasan diatas tersebut bisa kita lihat betapa merananya para pelaku dunia olahraga di tingkat Nasional maupun daerah akibat wabah pandemi covid-19. Sejak masa pandemi ini tingkat kejahatan semakin tinggi baik kejahatan seperti pencurian motor, pengedaran narkoba,jambret di jalan raya, perampokan di Indonesia yang hampir pelakunya anak anak usia remaja. Miris sekali hati ini mendengar hal-hal semacam itu.

Sumber permasalahan di atas tersebut membuat saya sebagai akademisi tergerak peduli terhadap daerah saya yang hampir $80 \%$ para remaja di daerah saya hidup dan bergantung pada kompetisi tarkam. Saya bersama anggota pengabdian yang tergerak sebagai pelaku akademisi, yang kebetulan terjun di berbagai dunia usaha, mengapa tidak untuk memberdayakan para pemain yang notabenenya adalah pengangguran, mahasiswa, kuli bangunan, pekerja paruh waktu untuk ikut bekerjasama, guna menambah pengetahuan dan ekonomi para pemain tersebut. Dalam program Kampus Merdeka dan bagian dari program Kemendikbud untuk memperkuat kemandirian ekonomi Nasional dan mendukung percepatan ekonomi digital.

FIKKM sebagai satu-satunya fakultas di lingkungan UNDIKMA yang telah menunjukkan perkembangannya yang terus maju, inovatif dan peduli pada masyarakat dari sejak awal berdiri hingga sekarang, sehingga saya selaku akademisi, yang beranggotakan pemegang mata kuliah kewirausahaan tahun akademik 2020/2021. Ingin memberikan perhatian lebih pada pemain remaja di lingkungan masyarakat, agar tidak terjerumus ke hal-hal negatif yang melanggar hukum. Sehingga dalam upaya tersebut diambil langkah memberikan sosialisasi, motivasi, pelatihan kewirausahaan berbentuk jajanan tradisional dan alat olahraga tradisional, serta pelatihan marketing. Mengingat telah di bangunnya sirkuit Mandalika Internasional Lombok, sehingga terpikir sesuatu yang berbau budaya dan tradisional akan bisa menjadi primadona baik pada masa pandemi maupun pada masa gelaran balapan berlangsung. Beberapa hal di atas tersebut tercetuslah tema pengabdian masyarakat dengan tema "Sosialisasi Berwirausaha, Guna Menambah Penghasilan Pemain Sepakbola PSGS Gunungsari Ketika Masa Kompetisi Diliburkan Akibat Pandemi Covid-19”. 


\section{Metode}

\section{Persiapan Kegiatan} dari:

Persiapan Kegiatan yang dilakukan terdiri

\section{Mekanisme sebelum pelaksanaan kegiatan}

Sebelum terjun ke lapangan, maka perlu dilakukan beberapa hal sebagai bentuk persiapan, antara lain:

a) Melakukan verifikasi instansi yaitu klub PSGS Gunungsari tempat diadakan pengabdian masyarakat ini sesuai dengan prosedur dan prokes yang berlaku di Lembaga Penelitian dan Pengabdian kepada Masyarakat di UNDIKMA.

b) Melakukan pendataan kepada peserta program terkait dengan kegiatan yang akan dilaksanakan.

2. Materi "Sosialisasi Berwirausaha, Guna Menambah Penghasilan Pemain Sepakbola PSGS Gunungsari Ketika Masa Kompetisi Diliburkan Akibat Pandemi Covid-19" disampaikan oleh TIM Anggota (materi kewirausahaan di sampaikan oleh Rusdiana Yusuf, M.Pd, selaku dosen kewirausahaan di FIKKM UNDIKMA., serta pelatihan pembuatan jajanan tradisional dan alat olahraga tradisional di sampaikan oleh Nune Wire Panji Sakti, M. Pd, selaku pemilik brand Jajanan Tradisional SATIA).

\section{Pelaksanaan Program}

Adapun tahapan-tahapan pelaksanaan program didesain sebagai berikut:

1. Mempersiapkan tim yang akan terjun langsung ke lapangan yaitu 2 dosen sebagai pemateri sedangkan 1 dosen lainnya bertanggung jawab pada peralatan dan perlengkapan.

2. Memberikan materi berupa "Sosialisasi Berwirausaha, Guna Menambah Penghasilan Pemain Sepakbola PSGS Gunungsari Ketika Masa Kompetisi Diliburkan Akibat Pandemi Covid-19" dengan durasi 60 menit, kemudian dilanjutkan dengan sesi tanya jawab antara peserta dan pemateri.

3. Pelatihan pembuatan jajanan tradisional brand SATIA.
4. Memberikan pelatihan menjual brand jajanan tradisional SATIA dan alat olahraga tradisional secara online maupun offline.

5. Catatan: Panitia pelaksana pengabdian dan peserta harus taat protokol kesehatan

\section{Hasil dan Pembahasan}

Hasil

Pengabdian kepada masyarakat yang telah kami lakukan mengenai "Sosialisasi Berwirausaha, Guna Menambah Penghasilan Pemain Sepakbola PSGS Gunungsari Ketika Masa Kompetisi Diliburkan Akibat Pandemi Covid-19" (Gambar 1), melalui kegiatan bersama adalah sebagai berikut:

1. Memberikan pengetahuan, dampak dan keuntungan dalam berwirausaha ketika pandemic Covid-19 melanda dan memberikan motivasi berpikir ketika sudah dimulainya gelaran balapan Internasional Mandalika Lombok, sehingga munculah keinginan untuk berwirausaha dengan memproduksi jajanan tradisional yang dinaungi brand SATIA dan alat olahraga tradisional untuk dijadikan bahan berwirausaha.

2. Memberikan pelatihan membuat jajanan tradisional SATIA dan alat olahraga tradisional pemain klub PSGS Gunungsari sangatlah antusias sekali sehingga proses berjalan dengan baik dan menghasilkan produk jadi berupa Dodol Nangka SATIA, Dodol Pangan SATIA, Jaje Sagon SATIA, dan Jaje Nyambu' SATIA serta alat olahraga tradisional berupa enggrang dan mainan kunci tradisional, yang semuanya menggunakan olahan mudah ditemukan dan harganya tidak mahal, serta diharapkan akan berkembang berbagai macam varian olahan yang lainnya (Gambar 2).

3. Memberikan bekal dalam belajar mendistribusikan dengan skala kecil secara perorangan maupun kelompok baik secara daring/ online maupun offline. 


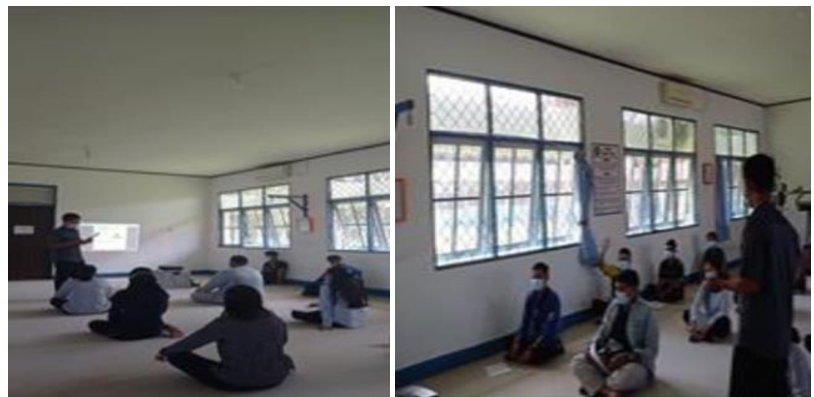

Gambar 1. Penyampaian materi dan Diskusi

Luaran Pada pengabdian kepada masyarakat klub PSGS Gunungsari adalah sebagai berikut:
1. Meningkatkan pengetahuan kepada pemain klub PSGS Gunungsari mengenai berwirausaha, cara membuat dan menghasilkan produk jadi berupa dodol nangka, dodol pangan, jaje sagon, dan jaje nyambu' serta alat olahraga tradisional dan mainan kunci.

2. Pengembangkan kreatifitas kepada pemain club PSGS Gunungsari mengenai cara mengolah jajanan tradisional brand SATIA dan alat olahraga tradisional serta mainan kunci.

3. Luaran yang dihasilkan dalam bentuk Proseding atau Jurnal ISSN.

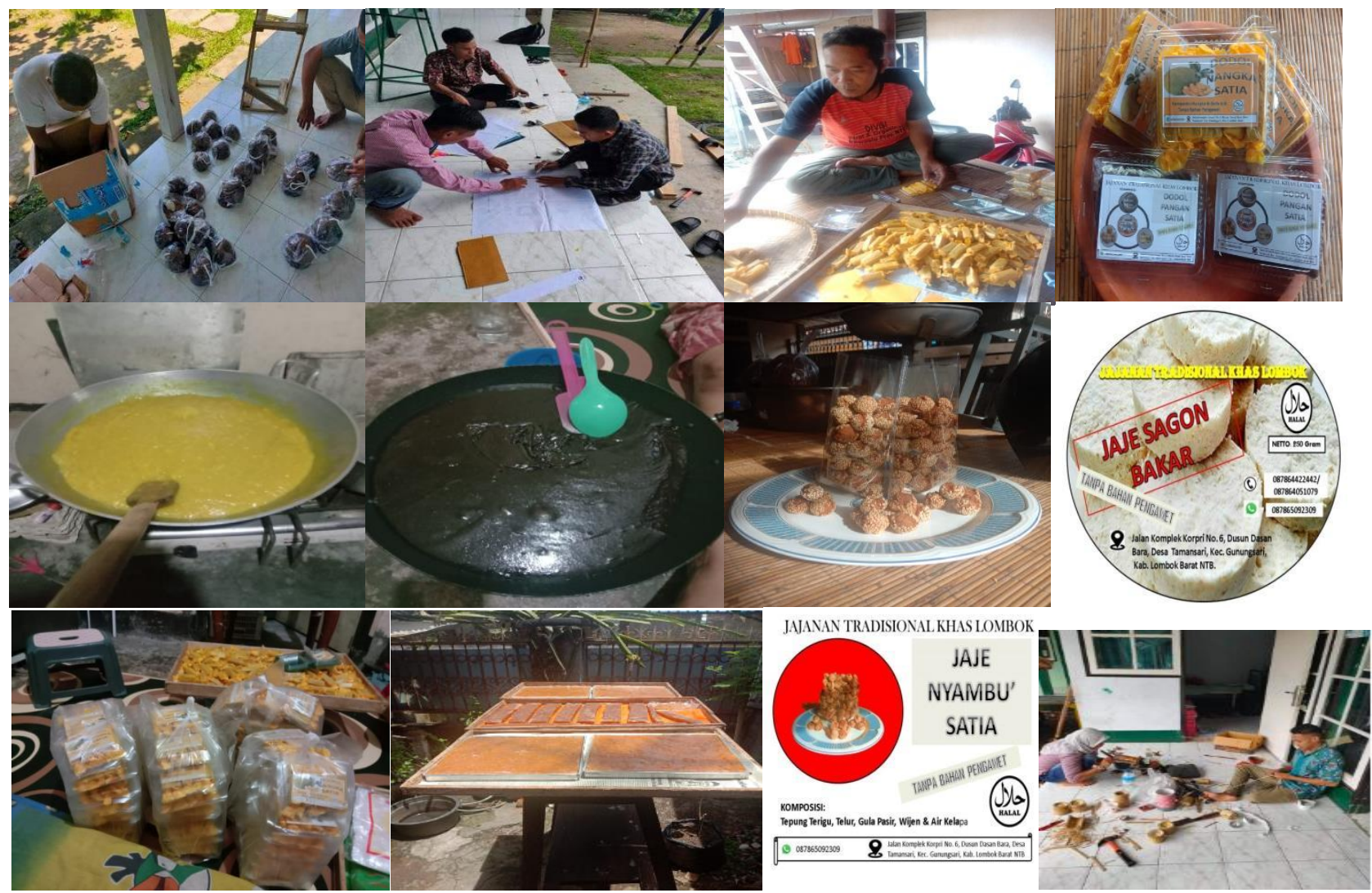

Gambar 2. Pelatihan pembuatan jajanan tradisional dan alat olahraga tradisional

\section{Kesimpulan}

Kegiatan pengabdian yang sudah dilakukan berupa berwirausaha yang meliputi pengetahuan, motivasi berwirausaha, pelatihan pembuatan produk jajanan tradisional SATIA dan alat olahraga tradisional serta mainan kunci, serta promosi dan pemasaran. Tim pengabdian berharap dengan adanya kegiatan ini dapat menjadi solusi di masa pandemi covid 19 serta menjadi pemasukan atau penghasilan baru pemain agar bisa hidup lebih layak untuk kedepannya.

\section{Daftar Pustaka}

Hernanda, R. (2021). Adversity quotient pada pelaku bisnis informal di masa pandemi coronavirus disease 2019 COVID-19 (Doctoral dissertation, Universitas Islam Negeri Maulana Malik Ibrahim). 
Lintang Kinasih, A. (2021). Pemrosesan Informasi pada Pelanggan Newsletter Catch Me Up dalam Mengonsumsi Berita Pendek COVID19 (Doctoral dissertation, Universitas Multimedia Nusantara).

Noviansyah, K. O., Busro, A., \& Priyono, E. A. (2016). Pelaksanaan Perjanjian Kerja Secara Lisan Antara Klub Dengan Pemain Pada Klub Futsal Atlas Muda Semarang. Diponegoro Law Journal, 5(4), 1-11.

Yuniati, M., \& Amini, R. (2020). Analisis Dampak Covid-19 Terhadap Daya Beli Masyarakat NTB. MPU PROCURATIO, 2(2 DESEMBER), 362-368. 